\title{
Safety of low-molecular-weight heparin compared to unfractionated heparin in hemodialysis: a systematic review and meta-analysis
}

Hind Harrak Lazrak ${ }^{1}$, Émilie René ${ }^{1}$, Naoual Elftouh ${ }^{1}$, Martine Leblanc ${ }^{2,3}$ and Jean-Philippe Lafrance ${ }^{1,2,3^{*}}$ (1)

\begin{abstract}
Background: Low molecular weight heparins (LMWH) have been extensively studied and became the treatment of choice for several indications including pulmonary embolism. While their efficacy in hemodialysis is considered similar to unfractionated heparin (UFH), their safety remains controversial mainly due to a risk of bioaccumulation in patients with renal impairment. The aim of this systematic review was to evaluate the safety of LMWH when compared to UFH for extracorporeal circuit (ECC) anticoagulation.
\end{abstract}

Methods: We used Pubmed, Embase, Cochrane central register of controlled trials, Trip database and NICE to retrieve relevant studies with no language restriction. We looked for controlled experimental trials comparing LMWH to UFH for ECC anticoagulation among end-stage renal disease patients undergoing chronic hemodialysis. Studies were kept if they reported at least one of the following outcomes: bleeding, lipid profile, cardiovascular events, osteoporosis or heparin-induced thrombocytopenia. Two independent reviewers conducted studies selection, quality assessment and data extraction with discrepancies solved by a third reviewer. Relative risk and $95 \% \mathrm{Cl}$ was calculated for dichotomous outcomes and mean weighted difference (MWD) with 95\% Cl was used to pool continuous variables.

Results: Seventeen studies were selected as part of the systematic. The relative risk for total bleeding was 0.76 (95\% Cl 0.26-2.22). The WMD calculated for total cholesterol was $-28.70 \mathrm{mg} / \mathrm{dl}(95 \% \mathrm{Cl}-51.43$ to -5.98 ), a WMD for triglycerides of $-55.57 \mathrm{mg} / \mathrm{dl}(95 \% \mathrm{Cl}-94.49$ to -16.66$)$ was estimated, and finally LDL-cholesterol had a WMD of $-14.88 \mathrm{mg} / \mathrm{dl}(95 \% \mathrm{Cl}-36.27$ to 6.51$)$.

Conclusions: LMWH showed to be at least as safe as UFH for ECC anticoagulation in chronic hemodialysis. The limited number of studies reporting on osteoporosis and HIT does not allow any conclusion for these outcomes. Larger studies are needed to evaluate properly the safety of LMWH in chronic hemodialysis.

Keywords: Bleeding, Chronic renal dialysis, Low molecular weight heparin, Meta-analysis, Systematic review, Unfractionated heparin

\footnotetext{
* Correspondence: jean-philippe.lafrance@umontreal.ca

${ }^{1}$ Maisonneuve-Rosemont Hospital Research Center, Montreal, Canada

${ }^{2}$ Department of Medicine, University of Montreal, Montreal, Canada

Full list of author information is available at the end of the article
} 


\section{Background}

Low molecular weight heparins (LMWH) are among the preferred anticoagulant for preventing and treating venous thrombosis [1]. A meta-analysis of randomized controlled trials showed similar efficacy between LMWH and unfractionated heparin (UFH) for acute deep venous thrombosis prevention, and no bleeding risk difference [2] with a reduced mortality rate in favor of LMWH. [2] LMWH are replacing UFH as the first line treatment for pulmonary embolism and unstable angina, a choice mainly due to their predictable effect and convenient use [3].

Despite the fact that the European Best Practice Guidelines for hemodialysis recommended the use of LWMH for the extracorporeal circuit (ECC) anticoagulation, UFH remains the most frequent choice for hemodialysis treatment in North America [4]. While cost may be the main argument for not using LMWH in hemodialysis, their safety remains a major concern. UFH is metabolized by both hepatic and renal pathways but LMWH are mainly cleared through the kidneys leading to a potential bioaccumulation and an increased risk of hemorrhage [5]. A meta-analysis conducted by Lim et al. evaluated the safety and efficacy of LMWH in hemodialysis, finding no difference between LMWH and UFH for both bleeding and thrombosis of the ECC. While the sample was large enough to evaluate efficacy (thrombosis), limited data was available to evaluate the risk of bleeding, leading to large confidence intervals (CI), and therefore limited conclusions [6].

UFH is known to modify the lipid profile, to induce osteoporosis, and to carry a risk of heparin-induced thrombocytopenia (HIT). However, the impact of LMWH on these outcomes in hemodialysis remains unclear [7].

The aim of this systematic review was to evaluate the safety of LMWH compared to UFH as an anticoagulant of the ECC among patients undergoing chronic hemodialysis. The primary outcomes were the risk of minor and major bleedings, cardiovascular events and osteoporotic fractures. Secondary outcomes were changes in lipid profile, osteoporosis and HIT.

\section{Methods}

Two independent reviewers (HHL and ER) conducted the study selection, validity assessment and data extraction with disagreement solved by a third reviewer (JPL).

\section{Performed searches}

Databases were screened to retrieve prospective experimental studies comparing LMWH to UFH for anticoagulation of the ECC during hemodialysis for patients with end-stage renal disease (ESRD). The search strategy was developed with a professional librarian. We searched Pubmed (from start up to January 2016), Embase (1974 to 2016 week 1), Cochrane central register of controlled trials (from start to January 2016), Trip database, the National Institute for Health and Care Excellence (NICE) and clinicaltrials.gov/ with no language restriction. Performed searches were conducted by one reviewer (HHL). Reference lists of selected studies were screened manually and authors were contacted when additional data was needed (HHL and ER) Additional file 1.

\section{Study selection}

Studies were selected if they fulfilled the following criteria: a) Patients were adults with ESRD undergoing chronic hemodialysis (incident or prevalent); b) LMWH was compared to UFH for anticoagulation of the ECC during hemodialysis; c) at least one of the outcomes of interest was reported (minor or major bleeding, lipid profile changes for total cholesterol, LDL-cholesterol, triglycerides, cardiovascular events, osteoporosis, osteoporotic fractures, HIT); d) the design was a prospective randomized or non-randomized cross-over or a parallel randomized study. A study was excluded if: a) it was a non-randomized parallel-design; b) it was using historical data; or c) the results were published more than once in which case only the most complete study was kept.

\section{Quality assessment}

Quality of each study was assessed using the Cochrane risk of bias tool [8] for randomized trials or the risk of bias in non-randomized studies (Robins-I) [9]. The Cochrane risk of bias tool evaluates the methodology of the study and the potential biases in the research question context. [8] There is no final score but results are reported as low, unclear or high risk of bias for different potential biases. The Robins-I uses a similar approach but is adapted to non-randomized trials.

\section{Data extraction}

A common form was used to ascertain extraction of the complete study characteristics and outcomes of interest as follows: a) bleeding events classified as major and minor when specified by the authors; b) cardiovascular events; c) LDL, total-cholesterol and triglycerides levels at start and end of study for both treatment and control; d) osteoporotic fractures; e) osteoporosis diagnostic; f) bone density changes; g) OPG/RANKL biomarkers affecting bone density; and h) HIT.

\section{Statistical analysis}

The weighted kappa statistics was used to assess between reviewers agreement for study selection and quality assessment [10]. We calculated relative risks (RR) and 95\% confidence intervals (CI) for dichotomous clinical data. A pooled weighted mean difference (WMD) and its $95 \%$ CI were used to compare continuous 
outcomes. The pooled overall effect for both RR and WMD was estimated using the method described by DerSimonian and Laird [11] with a random effect model for heterogeneous data. Heterogeneity was evaluated using the $\mathrm{I}^{2}$ statistic using a $60 \%$ significance threshold. Publication bias was assessed visually using a funnel plot and using the Egger test [12]. All analyses were performed with Stata IC 11.0.

\section{Sensitivity analyses}

The pooled WMD and 95\% CI were calculated based on the pre- and post-treatment measures using their standard deviations to derive the WMD's standard deviation [8]. In the main analysis, the correlation factor was fixed at 0.5 based on the assumption that repeated measures would be moderately correlated. We tested the robustness of this assumption with correlation factors of 0.3 and 0.8 as sensitivity analyses.

\section{Results}

\section{Identification and study selection}

From a total of 971, we identified 17 studies [13-28] that met our pre-defined selection criteria (Fig. 1). The interrater agreement was excellent with a weighted kappa of 0.94 for study selection. In the meta-analysis, we included nine studies [13-15, 22-24, 26-28] that recorded bleeding episodes and 11 studies [13, 17-21, 23, 24, 26-28] evaluating lipid changes. Of note, when a study evaluated the same outcome within two different groups of patients and different settings we considered each part of the article as an independent study for both the systematic review and the meta-analysis [17, 28]. All the non-English articles were translated but did not meet criteria. Five studies were with a randomized cross-over design [16, 22, 24, 27, 29], nine were non-randomized cross-over [13-15, 17, 19-21, $25,28]$ and three parallel design with randomization $[18,23,26]$. Two studies were excluded from the review since they reported the same results as studies included in the present review. Sabri et al. [30] was excluded for presenting the same data and results as Al-Saran et al. [13]. The same situation occurred between Schneider el al [31] and Schmitt el al [25].

\section{Characteristics of studies and patients}

Characteristics of studies are listed in Table 1. The number of patients ranged from five to 110, and followup ranged between one and 60 months. Various types of LMWH were used for the experimental arm, including nadroparin, enoxaparin, tinzaparin, dalteparin, certoparin and fraxiparin. Both men and women were included with

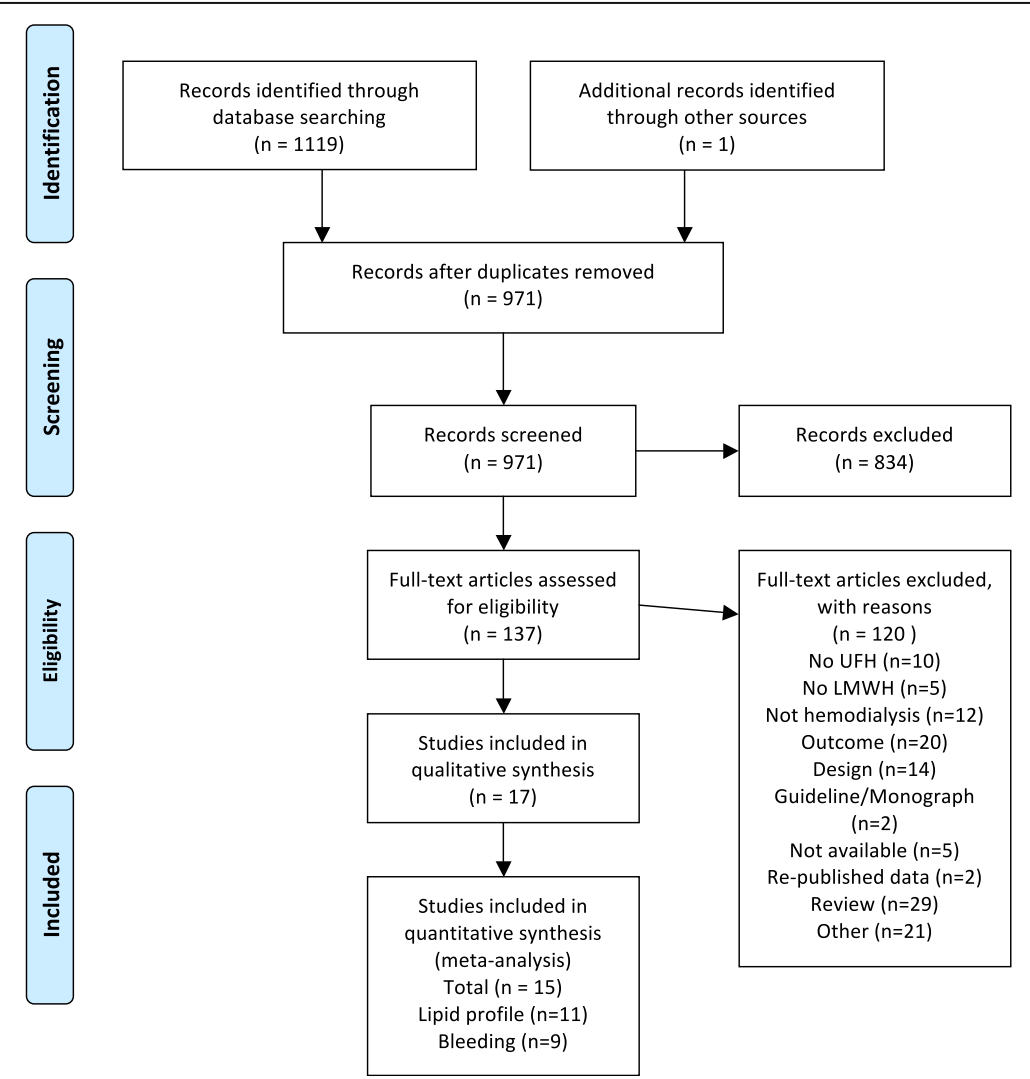

Fig. 1 Study selection flow chart adapted from the PRISMA flowchart model. *osteoporosis was not pooled with a meta-analysis (2 studies) 


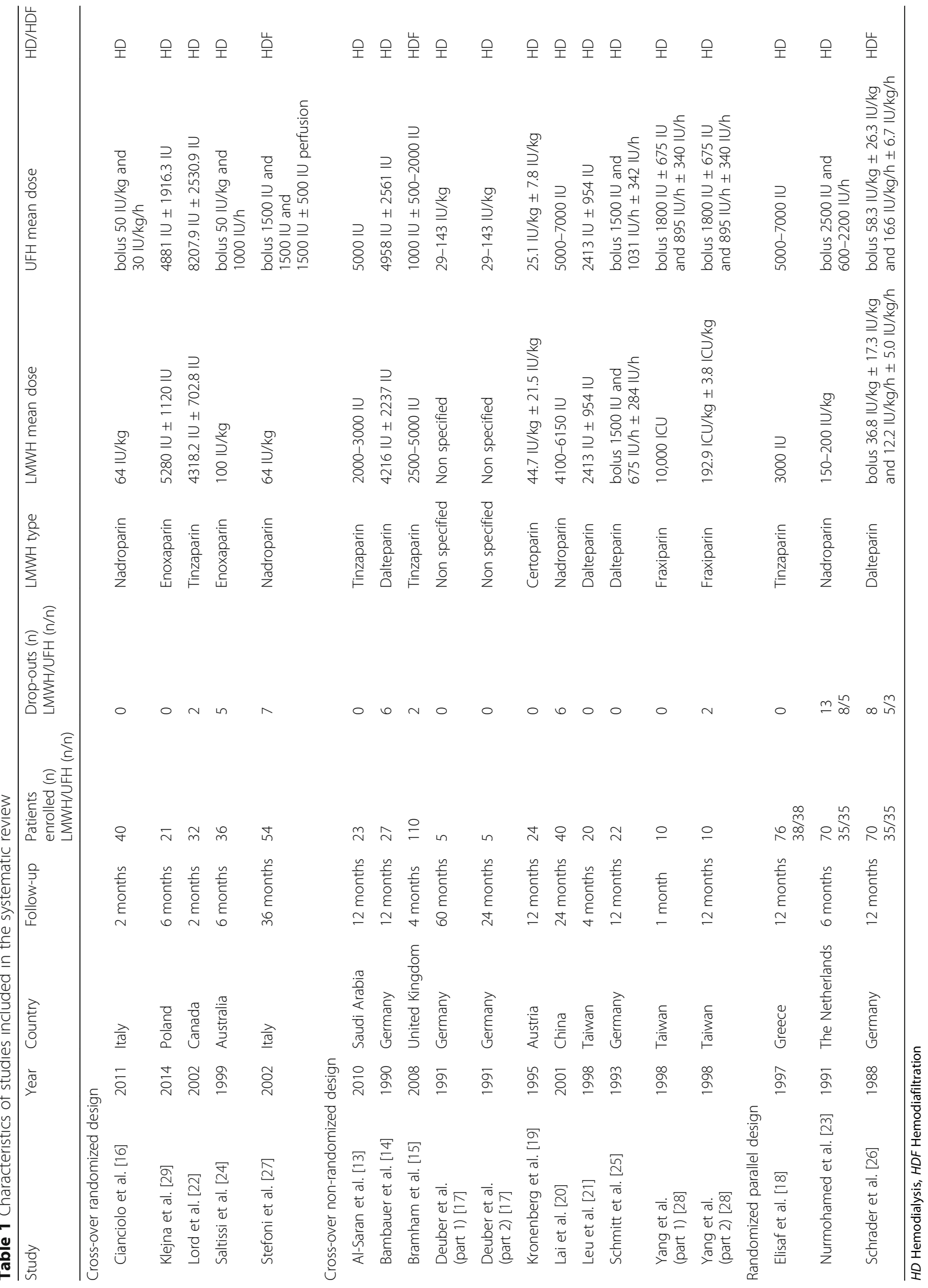


age ranging from 15 to 85 years. Exclusion criteria differed between studies but bleeding disorder was a recurrent criterion. Patient characteristics are detailed in Table 2. The most common dialysis schedule was a session of four hours thrice weekly. Hemodiafiltration procedure was also used in three studies [15, 26, 27].

\section{Quality assessment}

Based on the analysis with the Cochrane risk of bias tool for randomized studies (Fig. 2), we observed a high rate of potential performance bias mainly caused by a lack of blinding and only few measures to ensure similar care to the patients independently from heparin type. Blinding, or lack of it, could also affect outcome detection (detection bias). We judged that there was a high risk of bias when the outcome of interest was subjective. Bleeding events were categorized as being minor or major in eight out of nine studies, but most of the time no clear definition was provided except for one study. [27] The lack of definition made the evaluation of bleeding events subjective. In randomized trials, concealment was not specified, leading to an imprecise risk of selection bias for these studies. Overall, attrition and reporting biases were adequately handled through the trials (Fig. 2). Similarly, non-randomized cross-over studies had a moderate to high risk of outcome measurement when bleeding events evaluation was based on subjective assessment due to lack of clear outcome definition. The Robins-I tool points also to a missing data problematic due to drop-outs. (Fig. 3) The weighted kappa was 0.72 for Cochrane risk of bias tool and 0.69 for Robins-I, indicating a substantial agreement between raters.

\section{Synthesis of individual studies results}

Not all studies had a predefined definition of the outcome of interest. Bleeding outcome was specified in the method section in only half of the studies [15, 22, 24, 27, 28]. All except one [14] reported bleeding events as minor or major. Only Stefoni et al. provided a clear definition of major (melena, hematemesis and arterial epistaxis) and minor bleeding (venous epistaxis, subconjuctival hemorrhage or prolonged bleeding from the cannulation site after removal of the dialysis needle) [27]. For Bramham et al., a bleeding event was defined as a prolonged compression time or any other bleeding episode reported during or between dialysis sessions by the patients, including epistaxis or conjunctival bleeding [15]. Among all bleeding events, only two were categorized by the authors as major, and both occurred in the LMWH group. When combining both major and minor bleedings, $24(6.6 \%)$ events were recorded for LMWH compared to 31 (8.5\%) for UFH. Bleeding outcomes are presented in Table 3.
Cardiovascular events were reported in two studies; while Bambauer et al. [14] recorded two events with LMWH and three for UFH, Schrader et al. [26] observed two events with LMWH and one event with UFH. The majority of the studies showed a decrease in lipid levels using LMWH except for three which reported either an increase or no changes for cholesterol, [19, 26] LDLcholesterol $[19,24]$ and triglycerides $[24,26]$. The beneficial effect on lipids was less pronounced when using UFH where cholesterol, LDL-cholesterol and triglycerides increased or remained stable in five, [17, 21, 24-26] three $[21,24,25]$ and six $[17,21,25-28]$ studies, respectively (Tables 4-S1-S2).

No study evaluated the incidence of osteoporotic fractures. Osteoprotegerin (OPG) and receptor activator of nuclear factor- $\mathrm{kB}$ ligand (RANKL) levels were measured in two studies. The OPG/RANKL system is involved in bone metabolism. No significant difference between LMWH and UFH (Additional file 2: Table S3) was found [16, 29]. Lai et al. [20] measured the bone densitometry with dual energy X-ray and observed an increase of bone mass density (BMD) in ward's triangle by $0.75 \%$ after switching to LMWH. This increase did not reach statistical significance $(p=0.11)$. The mean BMD in the same region decreased by $2.38 \%$ after patients were back on UFH [20]. They did not observe a similar trend for the other sites investigated.

Bramham et al. [15] reported that they did not observe any case of thrombocytopenia among their patients during the study follow-up for both LMWH and UFH.

\section{Meta-analysis results}

Schrader et al. [26] and Yang et al. [28] were excluded from the analysis since they did not have any bleeding event in both LMWH and UFH groups. The overall RR for total bleeding (minor and major) with LMWH compared to UFH was 0.76 (95\% CI: 0.26, 2.22) using a random effect model. The $\mathrm{I}^{2}$ statistic for heterogeneity was statistically significant $(p=0.018)$ (Fig. 4a). Compared to UFH, LMWH showed lower cholesterol level, with a pooled WMD of $-28.70 \mathrm{mg} / \mathrm{dl}$ (95\% CI: $-51.43,-5.98)$ (Fig. 4c). A pooled WMD of $-55.57 \mathrm{mg} / \mathrm{dl}(95 \% \mathrm{CI}$ : -94.49, -16.66) was calculated for triglycerides showing lower levels in the LMWH group compared to UFH (Fig. 4d). A similar trend was observed with LDLcholesterolbut the results were not statistically significant (pooled WMD: $-14.88 \mathrm{mg} / \mathrm{dl}$ (95\% CI: -36.27 , 6.51)) (Fig. 4b). Results were pooled using random effect model as the heterogeneity test was statistically significant. Because of the small number of studies, visual interpretation of the funnel plots to assess possible publication bias was inconclusive (Additional file 2). The Egger test results indicated a potential publication bias (data not presented). 
Table 2 Participants characteristics

\begin{tabular}{|c|c|c|c|c|c|c|}
\hline Study & $\begin{array}{l}\text { Mean age }+ \text { SD } \\
\text { (years) }\end{array}$ & $\begin{array}{l}\text { Age range } \\
\text { (years) }\end{array}$ & $\begin{array}{l}\text { Male/Female } \\
(n / n)\end{array}$ & $\begin{array}{l}\text { Dialysis duration } \\
\text { and frequency }\end{array}$ & Inclusion criteria & Exclusion criteria \\
\hline \multicolumn{7}{|c|}{ Cross-over with randomization } \\
\hline Cianciolo et al. & $63.3 \pm 7.2$ & $42-72$ & $21 / 19$ & $4 \mathrm{~h} 3 \times / \mathrm{wk}$ & $\begin{array}{l}\text { chronic } H D \text {, } \\
\text { age } 18+\text {, stable, AVF }\end{array}$ & $\begin{array}{l}\text { gastrointestinal bleeding, acute } \\
\text { cardiovascular event } 3 \text { months before, } \\
\text { malignancy, coagulation disorders, } \\
\text { DVT, immunosupressive therapy, acute } \\
\text { vasculitis, liver disease, active infection, } \\
\text { diabetes, enrolled in other clinical trial }\end{array}$ \\
\hline Klejna et al. & 68.2 & $44-82$ & $11 / 10$ & $4-5$ h $3 \times / w k$ & Chronic HD & $\begin{array}{l}\text { HIV, Hepatitis B, Hepatitis C, VTE, } \\
\text { gastrointestinal bleeding, coagulation } \\
\text { disorders }\end{array}$ \\
\hline Lord et al. & $66.6 \pm 14.8$ & NS & $17 / 15$ & $4 \mathrm{~h} 3 \times / \mathrm{wk}$ & Chronic HD & $\begin{array}{l}\text { Patients with catheters, with bleeding } \\
\text { diathesis in last } 3 \text { months, with } \\
\text { thrombocytopenia, hepatic failure, oral } \\
\text { anticoagulation (but not antiplatelets) }\end{array}$ \\
\hline Saltissi et al. & NS & $22-85$ & $17 / 19$ & $3-5$ h $3 \times / w k$ & Chronic HD & $\begin{array}{l}\text { bleeding disorders, anticoagulation } \\
\text { therapy (warfarin, aspirin) }\end{array}$ \\
\hline Stefoni et al. & $63.7 \pm 7$ & NS & $39 / 15$ & $4 \mathrm{~h} 3 \times / \mathrm{wk}$ & $\begin{array}{l}\text { Chronic HD for at } \\
\text { least } 12 \text { months }\end{array}$ & $\begin{array}{l}\text { active gastrointestinal bleeding, } \\
\text { myeloproliferative disorders, } \\
\text { malignant diseases, hereditary } \\
\text { deficiency of coagulation factors, } \\
\text { LAC phenomenon, antiphospholipid } \\
\text { syndrome }\end{array}$ \\
\hline \multicolumn{7}{|c|}{ Cross-over without randomization } \\
\hline Al-Saran et al. & $46.83 \pm 14.63$ & NS & $17 / 6$ & $3-4$ h $3 \times / w k$ & $\begin{array}{l}\text { at least } 6 \text { months } \\
\text { on HD prior to study }\end{array}$ & $\begin{array}{l}\text { bleeding disorders, anemia with } \\
\text { hemoglobin levels less than } 10 \mathrm{~g} / \mathrm{dL} \text {, } \\
\text { recent trauma, surgery, infectious } \\
\text { disease or hemorrhagic disorder } \\
\text { (<1 month) in addition to those } \\
\text { receiving oral or other forms of } \\
\text { anticoagulant therapy (e.g. warfarin, } \\
\text { aspirin), or drugs that could affect } \\
\text { heparin activity (e.g. tetracyclines, } \\
\text { digitalis, and antihistamines) }\end{array}$ \\
\hline Bambauer et al. & 60 & NS & $12 / 15$ & NS & Chronic HD & NS \\
\hline Bramham et al. & $61 \pm 15$ & NS & $65 / 45$ & $3-4$ h $3 \times / w k$ & $\begin{array}{l}\text { Chonic HD on } \\
\text { monitoring shift }\end{array}$ & $\begin{array}{l}\text { Renal transplant, transferred to satellite } \\
\text { unit, switched to PD, on warfarin }\end{array}$ \\
\hline Deuber et al. (part 1) & $53 \pm 7$ & $47-65$ & NS & $4 \mathrm{~h} 3 \times /$ wk & $\begin{array}{l}\text { chronic } \mathrm{HD} \text { for at } \\
\text { least } 18 \text { months }\end{array}$ & NS \\
\hline Deuber et al. (part 2) & $50 \pm 18$ & $20-67$ & NS & $4 \mathrm{~h} 3 \times / \mathrm{wk}$ & $\begin{array}{l}\text { chronic } \mathrm{HD} \text { for at } \\
\text { least } 18 \text { months }\end{array}$ & NS \\
\hline Kronenberg et al. & $44.7 \pm 16.8$ & NS & $13 / 11$ & $3.5-5$ h $3 \times / w k$ & in pre-dialysis & $\begin{array}{l}\text { diabetes, bleeding disorders, oral } \\
\text { anticoagulants, lipid lowering drugs }\end{array}$ \\
\hline Lai et al. & $42.2 \pm 5.2$ & $24-60$ & $25 / 15$ & $10-16 \mathrm{~h} / \mathrm{wk}$ & Chronic HD & diabetes, primary hyperlipidemia \\
\hline Leu et al. & $57.8 \pm 9.8$ & NS & $7 / 13$ & $4 \mathrm{~h} 3 \times / \mathrm{wk}$ & $\begin{array}{l}\text { Chronic HD at } \\
\text { least } 6 \text { months }\end{array}$ & $\begin{array}{l}\text { pts with lipid lowering drugs except } \\
\text { non-diabetic pts. under lovastatin for } \\
>6 \text { months, known hemorrhagic } \\
\text { diathesis, low platelet count, liver } \\
\text { insufficiency, hypersensitivity to } \\
\text { heparin }\end{array}$ \\
\hline Schmitt et al. & 58.6 & $37-72$ & $13 / 9$ & $4-5.8 \mathrm{~h}$ & $\begin{array}{l}\text { chronic HD, } \\
\text { cholesterol } \\
>200 \mathrm{mg} / \mathrm{dL}\end{array}$ & $\begin{array}{l}\text { diabetes, concomittant drug } \\
\text { treatment (lipid lowering drugs, } \\
\text { COX inhibitors) }\end{array}$ \\
\hline Yang et al. (part 1) & $44 \pm 15$ & NS & $7 / 3$ & $3 \times / w k$ & $\begin{array}{l}\text { chronic } \mathrm{HD} \text {, } \\
\text { non diabetic }\end{array}$ & NS \\
\hline Yang et al. (part 2) & $57 \pm 6.4$ & NS & $7 / 3$ & $3 \times / w k$ & $\begin{array}{l}\text { chronic HD with } \\
\text { diabetes type ॥ }\end{array}$ & NS \\
\hline
\end{tabular}


Table 2 Participants characteristics (Continued)

\begin{tabular}{|c|c|c|c|c|c|c|}
\hline \multicolumn{7}{|c|}{ Parallel with randomization } \\
\hline Elisaf et al. & NS & $15-61$ & NS & $4 \mathrm{~h} 3 \times /$ wk & chronic HD & $\begin{array}{l}\text { diabetes, hyperlipidemia } \\
\text { (primary or secondary) }\end{array}$ \\
\hline Nurmohamed et al. & NS & NS & NS & $4-6$ h 2-3x/wk & chronic HD & NS \\
\hline Schrader et al. & $\begin{array}{l}54.0 \pm 15.2 \\
(\mathrm{LMWH}) \\
51.6 \pm 17.9 \\
(\mathrm{UFH})\end{array}$ & NS & $\begin{array}{l}21 / 14 \\
(\text { LMWH) } \\
19 / 16 \text { (UFH) }\end{array}$ & NS & $\begin{array}{l}\text { pre-HD requiring } \mathrm{HD} \text {, } \\
\text { not on heparin in } \\
\text { prior } 3 \text { months }\end{array}$ & $\begin{array}{l}\text { bleeding disorders, needed } \\
\text { antiplatelets or anticoagulants }\end{array}$ \\
\hline
\end{tabular}

NS not specified, HD hemodialysis, PD peritoneal dialysis, hrs hours, wk. week, DVT deep venous thrombosis, VTE venous thromboembolism, AVF arteriovenous fistula

\section{Sensitivity analyses}

Using different correlation factors to calculate the standard deviation of the mean changes for cholesterol, LDLcholesterol and triglycerides rendered similar results. With a correlation factor of 0.3 the pooled WMD for cholesterol, triglycerides and LDL were, $-27.38 \mathrm{mg} / \mathrm{dl}$ (95\% CI: $-50.78,-3.98),-53.76 \mathrm{mg} / \mathrm{dl}$ (95\% CI: -94.98 , $-12.53)$ and $-14.49 \mathrm{mg} / \mathrm{dl}(95 \% \mathrm{CI}:-35.73,6.75)$ respectively. A correlation factor of 0.8 resulted in pooled WMD for cholesterol, triglycerides and LDL of $-32.25 \mathrm{mg} / \mathrm{dl}$ (95\% CI: $-55.08,-9.42),-60.78 \mathrm{mg} / \mathrm{dl}$ (95\% CI: -97.74, $-23.83)$ and $-15.49 \mathrm{mg} / \mathrm{dl} \quad(95 \% \mathrm{CI}:-37.56,6.57)$ respectively.

\section{Discussion}

This systematic review reports on safety of LMWH compared to UFH when used for anticoagulation of the extracorporeal circuit during hemodialysis. There was no statistical difference for risk of bleeding in the LMWH compared to the UFH group. We also showed lower levels of total cholesterol and triglycerides when exposed to LMWH compared to UFH. LDL-cholesterol levels tended to be lower using LMWH but the difference did not reach statistical significance. Because of the small numbers of studies, we were not able to estimate the differential risk of cardiovascular events, osteoporotic fractures and HIT.

A decade after the publication of the first metaanalysis published by Lim et al. [6], we conducted a new systematic review to re-evaluate LMWH bleeding risk in hemodialysis compared to UFH by including all new relevant studies. Lim et al. found similar overall bleeding risk ( $R R=0.96,95 \%$ CI: $0.27,3.43)$, a result that is consistent with our study. Our updated meta-analysis adds to this earlier study by narrowing the $\mathrm{CI}$ and reducing the upper limit from three to two, supporting that, at least, LMWH does not carry a higher risk of bleeding. Our results are also consistent with observed bleeding risk among patients without renal failure using LMWH for their primary indication [32, 33]. Renal-dependent clearance of LMWH remains a concern. A prospective observational cohort study evaluated the bioaccumulation of dalteparin when administered at the therapeutic dose twice a day. Patients with a glomerular filtration rate (GFR) inferior to $30 \mathrm{~mL} / \mathrm{min} / 1.73 \mathrm{~m}^{2}$ showed a significant bioaccumulation of dalteparin at the end of the study [34]. On the other hand, two studies were conducted among critically ill patients with severe renal

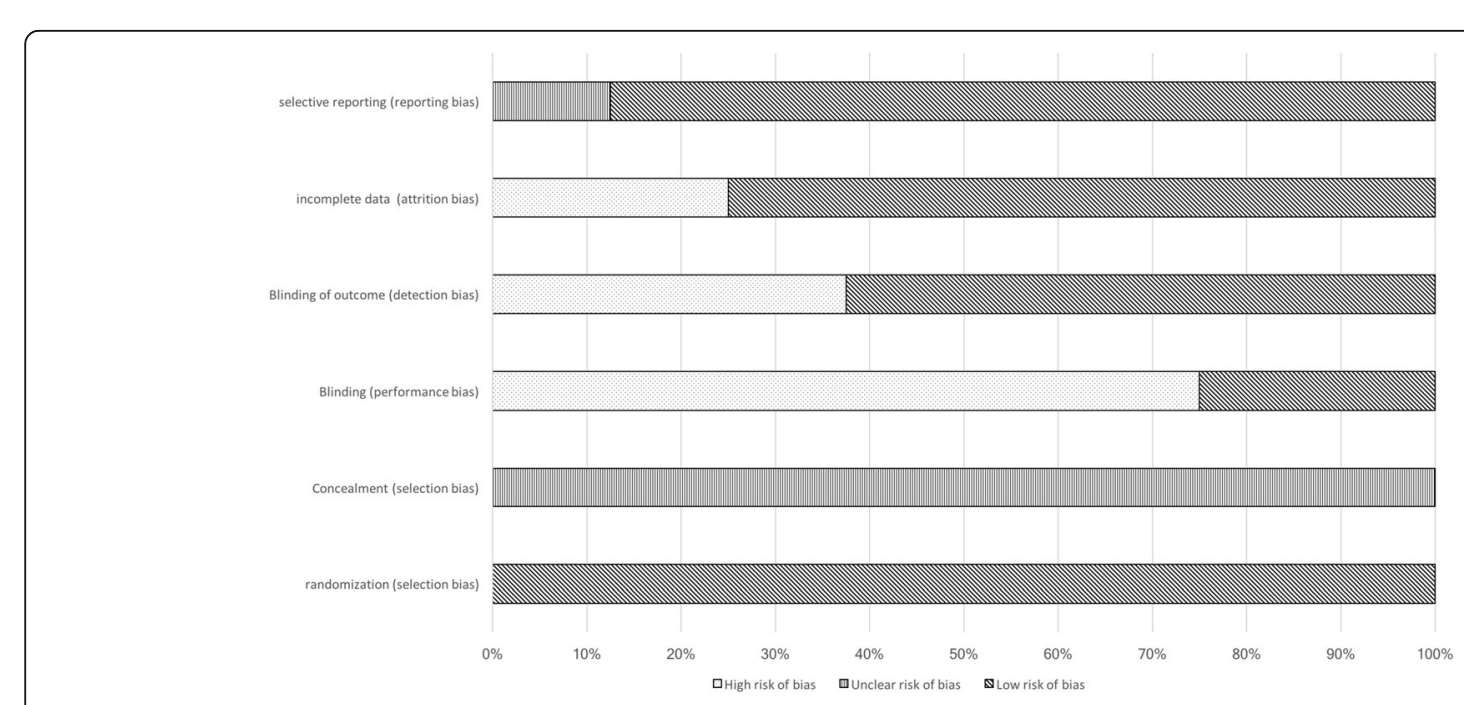

Fig. 2 Cochrane risk of bias tool diagram 


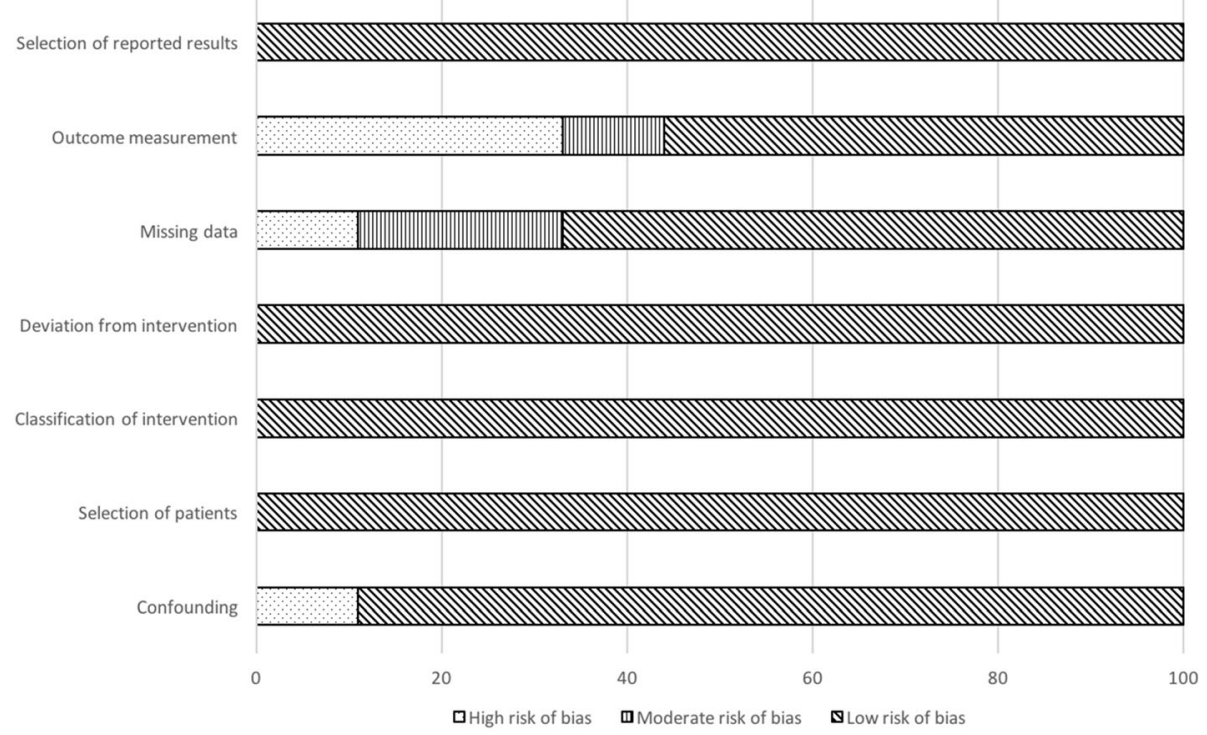

Fig. 3 Risk of Bias in non-randomized studies (Robins-l) diagram

insufficiency, and did not observe bioaccumulation of dalteparin using a prophylactic dose of 5000 IU once a day $[35,36]$. The later schedule is closer to the hemodialysis context.

No prior systematic review compared LMWH and UFH for cardiovascular events and lipid profile in hemodialysis. UFH is known to activate lipoprotein lipase and hepatic lipase and therefore to affect lipid profil [7]. Unfortunately, data on cardiovascular events were limited. Although it was demonstrated in the SHARP study [37] and a meta-analysis [38] that, for patients with chronic kidney disease, lowering LDLcholesterol by $38.61 \mathrm{mg} / \mathrm{dl}(1 \mathrm{mmol} / \mathrm{L})$ induced a reduction of $17 \%$ of major atherosclerotic events, in dialysis-dependent patients there is only a weak association between LDL-cholesterol level and the risk of cardiovascular event [39]. Indeed, low LDL-cholesterol level could be associated with a high risk of cardiovascular event in dialysis patients when there is coexistence of malnutrition and inflammation [40, 41]. While our results were in favor of LMWH, it remains uncertain whether the decrease would translate into lower cardiovascular events among ESRD patients.

Our meta-analysis is the first to compare LMWH and UFH for bone metabolism in hemodialysis. The exact mechanism involved in osteoporosis induced by UFH

Table 3 Bleeding events and relative risk with 95\% Cl for LMWH compared to UFH

\begin{tabular}{|c|c|c|c|c|}
\hline Study, year & $\begin{array}{l}\text { Total bleeding events } \\
\text { LMWH }(n / N)\end{array}$ & $\begin{array}{l}\text { Total bleeding events } \\
\text { UFH (n/N) }\end{array}$ & RR $(95 \% \mathrm{Cl})$ & Comments \\
\hline Al-Saran et al. & $3 / 23$ & $0 / 23$ & $7.00(0.38-128.33)$ & $\begin{array}{l}3 \text { minor bleedings with } L M W H \text {, } \\
\text { controlled with dose adjustment }\end{array}$ \\
\hline Bambauer et al. & $3 / 27$ & $6 / 27$ & $0.50(0.14-1.80)$ & $\begin{array}{l}\text { No indication if minor or major } \\
\text { bleeding events }\end{array}$ \\
\hline Bramham et al. & $0 / 110$ & $4 / 110$ & $0.11(0.01-2.04)$ & 4 minor bleeding episodes with UFH \\
\hline Lord et al. & $3 / 32$ & $8 / 32$ & $0.38(0.11-1.29)$ & $\begin{array}{l}\text { LMWH: } 1 \text { major and } 2 \text { minor } \\
\text { bleedings; UFH: } 8 \text { minor bleedings }\end{array}$ \\
\hline Nurmohamed et al. & $3 / 35$ & $0 / 35$ & $7.00(0.37-130.69)$ & 3 minor bleeding events with $\mathrm{LMWH}$ \\
\hline Saltissi et al. ${ }^{a}$ & $12 / 36$ & $6 / 36$ & $2.00(0.84-4.75)$ & $\begin{array}{l}\text { LMWH: } 1 \text { major and } 11 \text { minor bleedings; } \\
\text { UFH: } 6 \text { minor bleedings }\end{array}$ \\
\hline Stefoni et al. & $0 / 54$ & $7 / 54$ & $0.07(0.00-1.14)$ & 7 minor bleeding events with UFH \\
\hline Schrader et al. ${ }^{\mathrm{b}}$ & $0 / 35$ & $0 / 35$ & excluded & $\mathrm{n} / \mathrm{a}$ \\
\hline Yang et al. (part 1) ${ }^{\mathrm{b}}$ & $0 / 10$ & $0 / 10$ & excluded & $\mathrm{n} / \mathrm{a}$ \\
\hline Summary & $24 / 362$ & $31 / 362$ & $0.76(0.26-2.22)$ & \\
\hline
\end{tabular}

a Details of bleeding events extracted from Lim et al.

bStudies excluded due to "zero cells" in both LMWH and UFH groups 
Table 4 LDL-cholesterol weighted mean difference

\begin{tabular}{llll}
\hline Study & LMWH & UFH & WMD (95\% Cl) (mg/dl) \\
& mean change, SD (mg/dl) & mean change, SD (mg/dl) & $-10.83(-35.21,13.55)$ \\
\hline Al-Saran et al. ${ }^{a}$ & $-30.94 \pm 39.52$ & $-20.11 \pm 44.69$ & $-16.00(-31.69,-0.31)$ \\
Elisaf et al. & $-18 \pm 36.86$ & $-2 \pm 32.78$ & $28.80(8.83,48.77)$ \\
Kronenberg et al. $^{\text {a }}$ & $12.3 \pm 36.68$ & $-16.5 \pm 33.84$ & $3.87(-14.37,22.11)$ \\
Lai et al. $^{a}$ & $-2.70 \pm 36.93$ & $-6.57 \pm 45.82$ & $-67.67(-89.94,-45.40)$ \\
Leu et al. $^{\text {a }}$ & $-35.96 \pm 35.03$ & $31.71 \pm 36.80$ & $-1.16(-14.92,12.60)$ \\
Saltissi et al. ${ }^{a}$ & $0.39 \pm 29.01$ & $1.55 \pm 30.55$ & $-48.00(-77.33,-18.67)$ \\
Schmitt et al. & $-27 \pm 51.10$ & $21 \pm 48.12$ & $-14.88(-36.27,6.51)$ \\
\hline Summary & & &
\end{tabular}

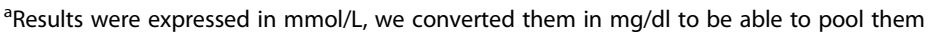

remains unclear. One hypothesis suggests a suppression of osteoblast formation and activation of osteoclasts promoting bone loss [5]. Unfortunately, no study compared osteoporotic fractures. Different studies presented the OPG/RANKL system as an actor of bone remodeling $[42,43]$. No difference was detected in the studies retrieved [16, 29]. While it is reported that LMWH cause less bone loss among pregnant women, these results were not replicated among hemodialysis patients [7]. Uncertainty was raised in the Kidney Disease Improving Global Outcomes (KDIGO) clinical guidelines in 2009 about the reliability of BMD measured with dual energy X-ray [44]. However a systematic review and meta-analysis conducted by Bucur et al. [45] showed
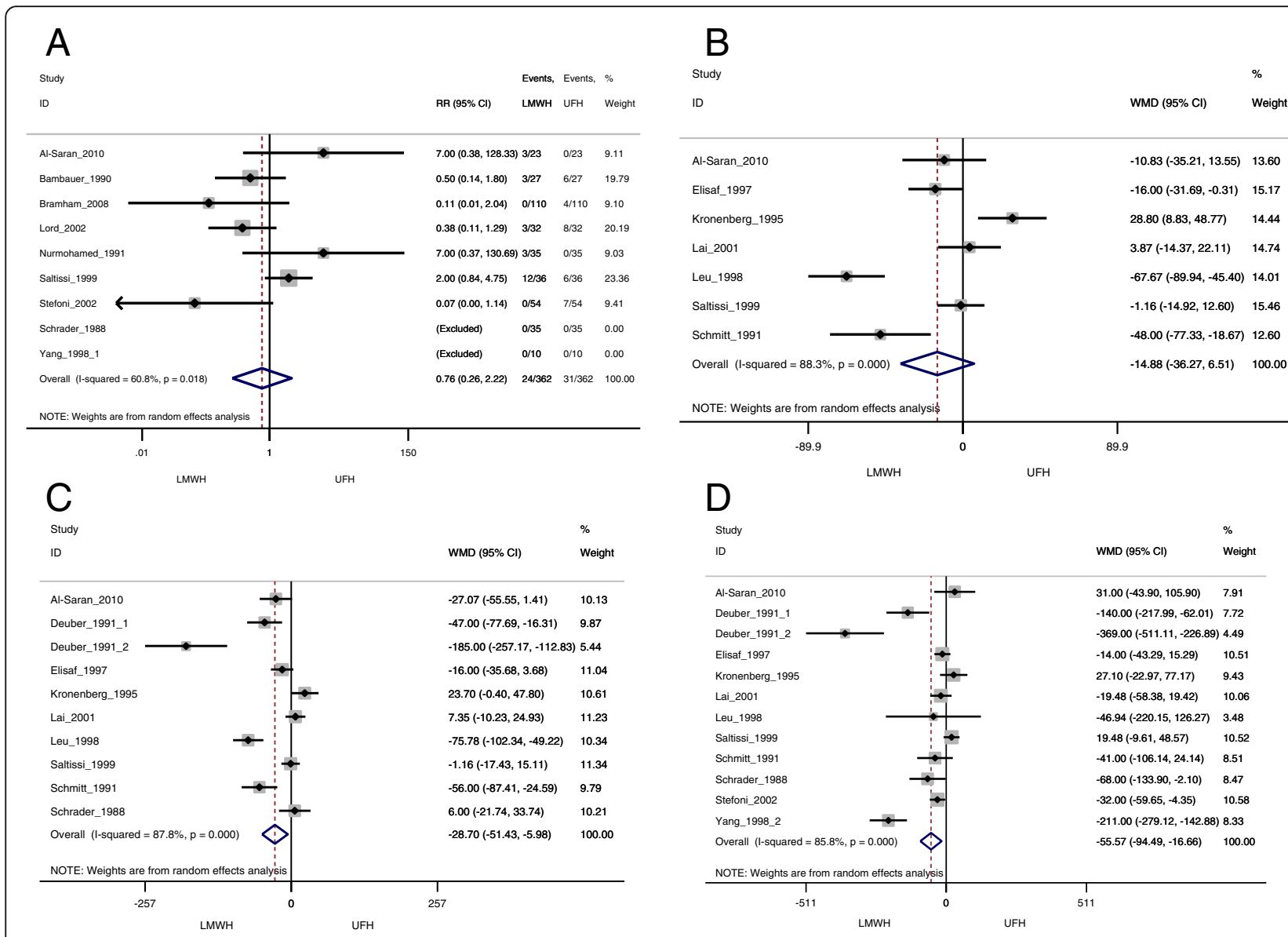

Fig. 4 Meta-analysis results for (a) total bleeding relative risk and confidence interval, (b) LDL-cholesterol, (c) Total cholesterol and (d) Triglycerides weighted mean difference and confidence interval for LMWH compared to UFH. Abbreviations: WMD, weighted mean difference, Cl, confidence interval 
that BMD is lower in chronic kidney disease (CKD) patients with fracture compared to CKD patients without fracture, suggesting that BMD could still be clinically relevant to evaluate fracture risk in CKD.

Thrombocytopenia is a rare but severe adverse reaction to heparin. Although Bramham et al. [15] did not observe any HIT; we cannot reach any conclusion regarding this outcome. The incidence of thrombocytopenia was reported between 1 and 3\% with UFH, while it was less than $1 \%$ with LMWH [46]. UFH binds to the platelet factor 4 (PF4). Antibodies then recognize this complex, which leads to an autoimmune reaction and thrombocytopenia [47]. Because a long chain of saccharides is needed to bind to PF4, and that LMWH are composed of short chains, it is believed that LMWH is less likely to form such complexes [48].

Our review has some limitations. Except for bleeding and cardiovascular events, we could not obtain data on every one of our primary outcomes. Our analyses were based on the secondary outcomes, and they might not be effective surrogates to infer on the main outcomes. The bleeding risk with LMWH may have been misestimated as some of the studies included an exploratory phase to determine the right LMWH dosage, which is partly based on occurrence of bleeding events, while UFH treatment arm did not go through such phase since patients were already stable under that regimen.

The potential publication bias detected must be taken into consideration when interpreting the results. Although the use of objective searching methods we could not eliminate this bias. Because of the lack of clear and consistent definition of major and minor bleeding in the retrieved studies, we opted to evaluate the risk of total bleeding. However, it would have been interesting to measure the risk of hemorrhage according to its severity, where major bleeding has a greater impact on the patient but also on the type of care needed [49]. A standardized definition of major and minor bleeding needs to be used in future investigations; such definition is already provided by the subcommittee on control of anticoagulation of the scientific and standardization committee of the international society on thrombosis and haemostasis [49].

The random effect model cannot compensate for the entire heterogeneity found between studies. High heterogeneity could be caused by multiple factors. The inclusion of different study designs in our review. We believe that the crossover and parallel-design should not be different for the measured outcomes in this context. Because of the small number of trials, it was not possible to analyze LMWH separately. LMWH have different pharmacokinetics and kidney failure does not alter similarly their elimination. For instance, enoxaparin might seem safe when there is clear evidence of its bioaccumulation [50, 51]. Finally, the trials used different doses and had variable follow-up time. The dosage, the use of low or high flux dialysis, types of membranes, hemodiafiltration and hemodialysis procedures, all these factors would contribute to the measured heterogeneity.

\section{Conclusion}

In conclusion, the available data does not allow to determine which heparin form is safer when used for anticoagulation of the extracorporeal circuit during hemodialysis. The risk of hemorrhage was not statistically significant when LMWH was compared to UFH, and lipid levels remained comparable or lower with LMWH. As for osteoporosis and thrombocytopenia, the data does not allow making a reliable comparison with UFH. The potential sources of bias discussed earlier and the quality level of the retrieved studies hinder the interpretation of observed results. LMWH have been used in hemodialysis for many years, but we are still in dire need of trials addressing the aforementioned limitations. Future studies need to use larger sample size during a sufficiently long follow-up and a clearer definition of the outcome measured to make their results usable and interpretable. Anticoagulation is mandatory for most patients undergoing hemodialysis treatments, and the choice of anticoagulation agent must be supported by stronger evidence.

\section{Additional files}

Additional file 1: Literature search strategies for Pubmed, Embase and Cochrane as used in this study are detailed in this document. (PDF $16 \mathrm{~kb}$ )

Additional file 2: Supplementary material providing the meta-analysis results for cholesterol (Table S1.) and triglycerides (Tables S2.), OPG/RANKL ratios (Table S3.), sensitivity analysis results (Table S4.) and funnel plots for publication bias. (PDF $177 \mathrm{~kb}$ )

\section{Abbreviations}

BMD: Bone mass density; Cl: Confidence intervals; CKD: Chronic kidney disease; ECC: Extracorporeal circuit; ESRD: End-stage renal disease; HIT: Heparin-induced thrombocytopenia; KDIGO: Kidney Disease Improving Global Outcomes; LMWH: Low molecular weight heparins; MWD: Mean weighted difference; PF4: Platelet factor 4; RR: Relative risks; UFH: Unfractionated heparin; WMD: Weighted mean difference

\section{Acknowledgements}

Not applicable.

\section{Funding}

This study was funded by Consortium de recherche en néphrologie de l'Université de Montréal.

\section{Availability of data and materials}

Not applicable.

\section{Authors' contributions}

This manuscript is co-authored by HHL (conception and design, analysis and interpretation of data, and writing of manuscript), ER (interpretation of data, writing of manuscript and critical appraisal of article), NE (analysis of data, and critical appraisal of article), ML (interpretation of data and critical appraisal of article), and JPL (conception and design, analysis and interpretation of data, and writing of manuscript). All authors read and approved the final manuscript. 


\section{Competing interests}

The authors declare that they have no competing interests.

\section{Consent for publication}

Not applicable.

Ethics approval and consent to participate

Ethics approval and consent waived. All the data presented in this review is from previously published studies.

\section{Publisher's Note}

Springer Nature remains neutral with regard to jurisdictional claims in published maps and institutional affiliations.

\section{Author details}

${ }^{1}$ Maisonneuve-Rosemont Hospital Research Center, Montreal, Canada. ${ }^{2}$ Department of Medicine, University of Montreal, Montreal, Canada. ${ }^{3}$ Division of Nephrology, Maisonneuve-Rosemont Hospital, 5415, boul. de I'Assomption, Montreal, QC H1T 2M4, Canada.

\section{Received: 29 December 2016 Accepted: 18 May 2017}

\section{Published online: 07 June 2017}

\section{References}

1. Kearon C, Akl EA, Comerota AJ, Prandoni P, Bounameaux H, Goldhaber SZ, et al. Antithrombotic therapy for VTE disease: Antithrombotic Therapy and Prevention of Thrombosis, 9th ed: American College of Chest Physicians Evidence-Based Clinical Practice Guidelines. Chest. 2012;141(2 Suppl):e419S-94S.

2. Gould MK, Dembitzer AD, Doyle RL, Hastie TJ, Garber AM. Low-molecularweight heparins compared with unfractionated heparin for treatment of acute deep venous thrombosis. A meta-analysis of randomized, controlled trials. Ann Intern Med. 1999:130(10):800-9.

3. Eikelboom JW, Anand SS, Malmberg K, Weitz JI, Ginsberg JS, Yusuf S. Unfractionated heparin and low-molecular-weight heparin in acute coronary syndrome without ST elevation: a meta-analysis. Lancet. 2000; 355(9219):1936-42.

4. Section V. Chronic intermittent haemodialysis and prevention of clotting in the extracorporal system. Nephrol Dial Transplant. 2002;17(Suppl 7):63-71.

5. Hirsh J, Warkentin TE, Shaughnessy SG, Anand SS, Halperin JL, Raschke R, et al. Heparin and low-molecular-weight heparin: mechanisms of action, pharmacokinetics, dosing, monitoring, efficacy, and safety. Chest. 2001;119(1 Suppl):64S-94S.

6. Lim W, Cook DJ, Crowther MA. Safety and efficacy of low molecular weight heparins for hemodialysis in patients with end-stage renal failure: a meta-analysis of randomized trials. J Am Soc Nephrol. 2004; 15(12):3192-206.

7. Davenport A. Review article: Low-molecular-weight heparin as an alternative anticoagulant to unfractionated heparin for routine outpatient haemodialysis treatments. Nephrology. 2009;14(5):455-61.

8. Higgins JPT, Green S (editors): Cochrane Handbook for Systematic Reviews of Interventions, Version 5.1.0 [updated March 2011] edn; 2011.

9. Sterne JA, Hernan MA, Reeves BC, Savovic J, Berkman ND, Viswanathan M, et al. ROBINS-I: a tool for assessing risk of bias in non-randomised studies of interventions. BMJ. 2016:355:14919.

10. Cohen J. A coefficient of agreement for nominal scales. Educ Psychol Meas. 1960;20(1):37-46.

11. DerSimonian R, Laird N. Meta-analysis in clinical trials. Control Clin Trials. 1986;7(3):177-88.

12. Egger M, Smith GD, Schneider M, Minder C. Bias in meta-analysis detected by a simple, graphical test. BMJ. 1997;315(7109):629-34.

13. Al-Saran KA, Sabry A, Taha M, Ghafour MA, Al Fawzan F. Profile of low molecular weight tinzaparin sodium for anticoagulation during hemodialysis. Saudi j Kidney Dis Transpl. 2010;21(1):43-9.

14. Bambauer R, Rucker S, Weber U, Kohler M. Comparison of low molecular weight heparin and standard heparin in hemodialysis. ASAIO Trans. 1990; 36(3):M646-9.

15. Bramham K, Varrier M, Asgari E, Makanjuola D. Comparison of Tinzaparin and unfractionated heparin as anticoagulation on haemodialysis: equal safety, efficacy and economical parity. Nephron Clin Pract. 2008;110(2):c107-13.
16. Cianciolo G, La Manna G, Donati G, Dormi A, Cappuccilli ML, Cuna V, et al Effects of unfractioned heparin and low-molecular-weight heparin on osteoprotegerin and RANKL plasma levels in haemodialysis patients. Nephrol Dial Transplant. 2011;26(2):646-52.

17. Deuber HJ, Schulz W. Reduced lipid concentrations during four years of dialysis with low molecular weight heparin. Kidney Int. 1991:40(3):496-500.

18. Elisaf MS, Germanos NP, Bairaktari HT, Pappas MB, Koulouridis El, Siamopoulos KC. Effects of conventional vs. low-molecular-weight heparin on lipid profile in hemodialysis patients. Am J Nephrol. 1997;17(2):153-7.

19. Kronenberg E, Konig P, Lhotta K, Steinmetz A, Dieplinger H. Low molecular weight heparin does not necessarily reduce lipids and lipoproteins in hemodialysis patients. Clin Nephrol. 1995;43(6):399-404.

20. Lai KN, Ho K, Cheung RC, Lit LC, Lee SK, Fung KS, et al. Effect of low molecular weight heparin on bone metabolism and hyperlipidemia in patients on maintenance hemodialysis. Int J Artif Organs. 2001:24(7):447-55.

21. Leu JG, Liou HH, Wu SC, Yang WC, Huang TP, Wu SC. Low molecular weight heparin in diabetic and nondiabetic hypercholesterolemic patients receiving long-term hemodialysis. J Formos Med Assoc. 1998;97(1):49-54

22. Lord H, Jean N, Dumont M, Kassis J, Leblanc M. Comparison between tinzaparin and standard heparin for chronic hemodialysis in a Canadian center. Am J Nephrol. 2002;22(1):58-66.

23. Nurmohamed MT, ten Cate J, Stevens P, Hoek JA, Lins RL, ten Cate JW. Long-term efficacy and safety of a low molecular weight heparin in chronic hemodialysis patients. A comparison with standard heparin. ASAIO Trans. 1991;37(3):M459-61.

24. Saltissi D, Morgan C, Westhuyzen J, Healy H. Comparison of low-molecularweight heparin (enoxaparin sodium) and standard unfractionated heparin for haemodialysis anticoagulation. Nephrol Dial Transplant. 1999;14(11):2698-703.

25. Schmitt $Y$, Schneider $H$. Low-molecular-weight heparin (LMWH): influence on blood lipids in patients on chronic haemodialysis. Nephrol Dial Transplant. 1993;8(5):438-42.

26. Schrader J, Stibbe W, Armstrong WW, Kandt M, Muche R, Kostering H, et al. Comparison of low molecular weight heparin to standard heparin in hemodialysis/hemofiltration. Kidney Int. 1988;33(4):890-6.

27. Stefoni S, Cianciolo G, Donati G, Coli L, La Manna G, Raimondi C, et al. Standard heparin versus low-molecular-weight heparin. A medium-term comparison in hemodialysis. Nephron. 2002;92(3):589-600.

28. Yang $C$, Wu T, Huang C. Low molecular weight heparin reduces triglyceride, VLDL and cholesterol/HDL levels in hyperlipidemic diabetic patients on hemodialysis. Am J Nephrol. 1998:18(5):384-90.

29. Klejna K, Naumnik B, Koc-Zorawska E, Mysliwiec M. Effect of unfractionated and low-molecular-weight heparin on OPG, sRANKL, and von Willebrand factor concentrations during hemodialysis. Clin Appl Thromb Hemost. 2014;20(4):433-41.

30. Sabry A, Taha M, Nada M, Al Fawzan F, Alsaran K. Anticoagulation therapy during haemodialysis: a comparative study between two heparin regimens. Blood Coagul Fibrinolysis. 2009;20(1):57-62.

31. Schneider $H$, Schmitt Y. Low molecular weight heparin: Influence on blood lipids in patients on chronic hemodialysis. [German]. Klin Wochenschr. 1991; 69(16):749-56

32. Koopman MM, Prandoni P, Piovella F, Ockelford PA, Brandjes DP, van der Meer J, et al. Treatment of venous thrombosis with intravenous unfractionated heparin administered in the hospital as compared with subcutaneous low-molecular-weight heparin administered at home. The Tasman Study Group. N Engl J Med. 1996;334(11):682-7.

33. Levine M, Gent M, Hirsh J, Leclerc J, Anderson D, Weitz J, et al. A comparison of low-molecular-weight heparin administered primarily at home with unfractionated heparin administered in the hospital for proximal deep-vein thrombosis. N Engl J Med. 1996;334(11):677-81.

34. Schmid P, Brodmann D, Odermatt Y, Fischer AG, Wuillemin WA. Study of bioaccumulation of dalteparin at a therapeutic dose in patients with renal insufficiency. J Thromb Haemost. 2009;7(10):1629-32.

35. Cook D, Douketis J, Meade M, Guyatt G, Zytaruk N, Granton J, et al. Venous thromboembolism and bleeding in critically ill patients with severe renal insufficiency receiving dalteparin thromboprophylaxis: prevalence, incidence and risk factors. Crit Care. 2008;12(2):R32.

36. Douketis J, Cook D, Meade M, Guyatt G, Geerts W, Skrobik Y, et al. Prophylaxis against deep vein thrombosis in critically ill patients with severe renal insufficiency with the low-molecular-weight heparin dalteparin: an assessment of safety and pharmacodynamics: the DIRECT study. Arch Intern Med. 2008;168(16):1805-12. 
37. Baigent C, Landray MJ, Reith C, Emberson J, Wheeler DC, Tomson C, et al. The effects of lowering LDL cholesterol with simvastatin plus ezetimibe in patients with chronic kidney disease (Study of Heart and Renal Protection): a randomised placebo-controlled trial. Lancet. 2011;377(9784):2181-92.

38. Baigent C, Blackwell L, Emberson J, Holland LE, Reith C, Bhala N, et al. Efficacy and safety of more intensive lowering of $L D L$ cholesterol: a meta-analysis of data from 170,000 participants in 26 randomised trials. Lancet. 2010;376(9753):1670-81.

39. Wanner C, Tonelli M. KDIGO Clinical Practice Guideline for Lipid Management in CKD: summary of recommendation statements and clinical approach to the patient. Kidney Int. 2014;85(6):1303-9.

40. Krane V, Winkler K, Drechsler C, Lilienthal J, Marz W, Wanner C, et al. Association of LDL cholesterol and inflammation with cardiovascular events and mortality in hemodialysis patients with type 2 diabetes mellitus. Am J Kidney Dis. 2009:54(5):902-11.

41. Liu Y, Coresh J, Eustace JA, Longenecker JC, Jaar B, Fink NE, et al. Association between cholesterol level and mortality in dialysis patients: role of inflammation and malnutrition. JAMA. 2004;291(4):451-9.

42. Lacey DL, Timms E, Tan HL, Kelley MJ, Dunstan CR, Burgess T, et al. Osteoprotegerin ligand is a cytokine that regulates osteoclast differentiation and activation. Cell. 1998;93(2):165-76.

43. Simonet WS, Lacey DL, Dunstan CR, Kelley M, Chang MS, Luthy R, et al. Osteoprotegerin: a novel secreted protein involved in the regulation of bone density. Cell. 1997;89(2):309-19.

44. Kidney Disease: Improving Global Outcomes (KDIGO) CKD-MBD Work Group. KDIGO clinical practice guideline for the diagnosis, evaluation, prevention, and treatment of Chronic Kidney Disease-Mineral and Bone Disorder (CKD-MBD). Kidney Int Suppl. 2009;(113):S1-130.

45. Bucur RC, Panjwani DD, Turner L, Rader T, West SL, Jamal SA. Low bone mineral density and fractures in stages 3-5 CKD: an updated systematic review and meta-analysis. Osteoporos Int. 2015;26(2):449-58.

46. Charif R, Davenport A. Heparin-induced thrombocytopenia: an uncommon but serious complication of heparin use in renal replacement therapy. Hemodial Int. 2006;10(3):235-40.

47. Visentin GP, Ford SE, Scott JP, Aster RH. Antibodies from patients with heparin-induced thrombocytopenia/thrombosis are specific for platelet factor 4 complexed with heparin or bound to endothelial cells. J Clin Invest. 1994;93(1):81-8.

48. Warkentin TE, Levine MN, Hirsh J, Horsewood P, Roberts RS, Gent M, et al. Heparin-induced thrombocytopenia in patients treated with low-molecularweight heparin or unfractionated heparin. N Engl J Med. 1995;332(20):1330-5.

49. Schulman S, Kearon C, Subcommittee on Control of Anticoagulation of the S, Standardization Committee of the International Society on T, Haemostasis. Definition of major bleeding in clinical investigations of antihemostatic medicinal products in non-surgical patients. J Thromb Haemost. 2005:3(4):692-4.

50. Johansen KB, Balchen T. Tinzaparin and other low-molecular-weight heparins: what is the evidence for differential dependence on renal clearance? Exp Hematol Oncol. 2013;2:21.

51. Hoffmann P, Keller F. Increased major bleeding risk in patients with kidney dysfunction receiving enoxaparin: a meta-analysis. Eur J Clin Pharmacol. 2012;68(5):757-65

\section{Submit your next manuscript to BioMed Central and we will help you at every step:}

- We accept pre-submission inquiries

- Our selector tool helps you to find the most relevant journal

- We provide round the clock customer support

- Convenient online submission

- Thorough peer review

- Inclusion in PubMed and all major indexing services

- Maximum visibility for your research

Submit your manuscript at www.biomedcentral.com/submit 